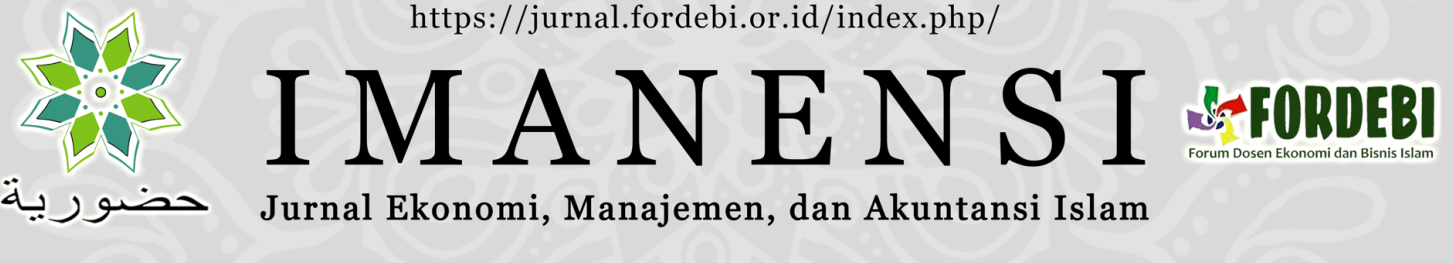

\title{
TINJAUAN KEUANGAN DAN NONKEUANGAN PEMBELAJARAN DARING
}

\author{
Sirajudin ${ }^{a, 1 *}$, Nurul Mukhlisah ${ }^{b, 2}$, Lea Emilia Faridac,3 \\ a,b,c Politeknik Negeri Banjarmasin, Jl. Brig Jend. Hasan Basri, Pangeran, Banjarmasin, Kalimantan \\ Selatan 70124 , Indonesia.
}

1sirajudin@poliban.ac.id*,2n.mukhlisah@poliban.ac.id, 3lea@poliban.ac.id

*Corresponding author

\begin{tabular}{ll}
\hline INFO ARTIKEL & Abstrak: Tinjauan Keuangan dan Nonkeuangan \\
IMANENSI & Pembelajaran Daring. Penelitian ini bertujuan menggali \\
Volume 6 & fenomena pembelajaran daring pada mahasiswa D3 \\
Nomor 1 & Akuntansi Poliban dalam tinjauan perspektif keuangan dan \\
Halaman 15-22 & nonkeuangan. Teknik analisis yang digunakan adalah \\
Malang, Maret 2021 & mentranskripsi hasil korespondensi dengan informan, \\
ISSN: 2339-1847 & dilanjutkan dengan mendeskripsikan atau menarasikan semua \\
e-ISSN: 2683-9968 & analisis kontekstual atas tinjauan keuangan dan nonkeuangan \\
& selama pembelajaran daring. Hasil penelitian mengungkapkan \\
Kronologi Artikel: & bahwa terjadi penghematan pengeluaran informan selama \\
Tanggal Masuk: & pembelajaran daring dari perspektif keuangan, namun dari \\
9 Februari 2021 & perspektif nonkeuangan para informan sebagai makhluk sosial \\
Tanggal Revisi: & kehilangan interaksi langsung, seperti berkumpul dengan \\
4 Maret 2021 & sesama kolega, lingkungan kampus beserta civitas akademika \\
Tanggal Diterima: & lainnya.
\end{tabular}

Kata Kunci:

Interaksi;

Keuangan;

Nonkeuangan;

Pembelajaran Daring;

Keywords:

Finance;

Interaction;

Non-financial;

Online learning;

\begin{abstract}
Online Learning Financial and non-Financial Overview. This study aims to explore the phenomenon of online learning among D3 Poliban Accounting students in a financial and non-financial perspective review. The analysis technique used is transcribing the results of correspondence with informants, followed by describing or narrating all contextual analyzes of financial and non-financial reviews during online learning. The results of the study revealed that there was savings in informants' expenditure during online learning from a financial perspective, but from a non-financial perspective, informants as social beings lost direct interactions, such as gathering with colleagues, the campus environment and other academics.
\end{abstract}

Disitasi sebagai: Sirajudin., Mukhlisah, N., \& Farida, L.E. (2021). Tinjauan Keuangan dan Nonkeuangan Pembelajaran Daring . IMANENSI: Jurnal Ekonomi, Manajemen, dan Akuntansi Islam, 6(1), 15-22. https://doi.org/10.34202/imanensi.6.1.2021.15-22.

\section{PENDAHULUAN}

Sejak mewabahnya penyebaran Covid19, terhitung pada 15 Maret 2020, pemerintah telah mengeluarkan edaran resminya agar sekolah dan perguruan tinggi melakukan proses pembelajaran dilakukan secara daring (dalam jaringan) atau online melalui surat edaran Kemendikbud No.1 tahun 2020 (Firman dan Rahayu, 2020; Handayani dan Wulandari, 2020; Laili, 2020; Windhiyana, 2020). Pembelajaran daring ini adalah pembelajaran yang dilakukan tanpa tatap muka secara langsung antara dosen dan mahasiwa, namun hanya dilakukan melalui 
online. Pembelajaran model ini bisa dilakukan melalui video conference, e-learning atau distance learning (Daniel, 2020; Lassoued dkk, 2020).

Pembelajaran daring ini sejatinya sudah dikenalkan oleh Dirjen Dikti sejak tahun 2014 dengan program PDITT atau Pembelajaran Daring Indonesia Terbuka dan Terpadu yang di tahun 2016 berganti menjadi SPADA atau Sistem Pembelajaran Daring. SPADA tersebut bertujuan menciptakan akses yang merata sehingga menghasilkan mutu pembelajaran yang berkualitas di Perguruan Tinggi (Novita dan Hutasuhut, 2020). Adapun media atau platform pembelajaran daring ini bisa berupa Learning Management System (LMS) atau Virtual Learning Environment (VLE) seperti Moodle, Edmodo, dan sejenisnya yang sudah digunakan terbatas pada beberapa perguruan tinggi. Artinya hanya sebagian para akademisi yang menggunakan media pembelajaran daring tersebut.

Kondisi pandemik Covid-19 memaksa pembelajaran daring diadopsi segera oleh seluruh perguruan tinggi yang ada di Indonesia. Hal tersebut tentunya menjadi perhatian serius di tengah ketidaksiapan mayoritas para akademisi dan elemen lainnya dalam menjalankan pembelajaran daring ini. Selain ketidaksiapan tersebut hal yang juga menjadi kendala dan isu penting lainnya adalah kelancaran jaringan internet dalam pembelajaran daring. Kelancaran jaringan internet di era industri digital tentunya selalu sejalan dengan perubahan pengorbanan financial yang harus dilakukan pengguna jaringan.

Perubahan pengorbanan financial tersebut tentunya juga dialami oleh para pengguna jasa pendidikan di lingkungan Politeknik Negeri Banjarmasin, termasuk pada mahasiswa, yang harus belajar dari rumah sejak pandemi Covid 19. Hal ini lah yang ingin digali terkait pandangan mahasiswa terhadap perubahan financial selama pembelajaran daring, sehingga penelitian ini berusaha mengungkap tinjauan keuangan dan nonkeuangan atas pembelajaran daring perspektif mahasiswa D3 Akuntansi Politeknik Negeri Banjarmasin.

Hasil penelitian ini diharapkan bisa memberikan masukan terkait kebijakan pemilihan pendekatan pembelajaran yang mengoptimalkan potensi semua pihak yang terlibat dan pencapaian pembelajaran.

\section{METODE}

Penelitian ini mengambil situs di lingkungan Program Studi D3 Akuntansi Politeknik Negeri Banjarmasin. Pendekatan kualitatif digunakan dengan menganalisis secara mendalam atas fenomena pembelajaran daring perspektif mahasiswa D3 Akuntansi Poliban. Penelitian kualitiatif bertujuan memahami secara mendalam fenomena atau gejala sosial dengan memberikan perhatian yang besar atas gambaran utuh suatu fenomena yang diteliti. Pemahaman mendalam tersebut diharapkan bisa menghasilkan temuan yang bisa berupa asumsi, penguatan atau anomaly atas sebuah teori, bahkan tidak jarang menghasilkan sebuah teori.

Metode penelitan kualitatif yang digunakan nanti adalah etnometodologi yang merupakan salah satu pendekatan kualitatif interpretif yang berusaha melihat fenomena atau gejala sosial dari sudut pandang anggota suatu komunitas terkait keteraturan dan keseimbangan mereka dalam berinteraksi. Secara umum data pada penelitian kualitatif didapatkan melalui pengamatan (observasi), komunikasi virtual dan dokumentasi. Pada penelitian ini data yang dikumpulkan dan diperoleh kebanyakan dengan menggunakan media sosial sebagai pengganti wawancara mendalam yakni dengan menggunakan pertanyaan terbuka (peneliti mengeksplor/menggali jawaban dari informan secara mendalam). Jawaban informan tersebut direkam berupa catatan atau dokumen elektronik maupun video untuk mempermudah pada proses analisis data. 
Setelah data korespondensi dikumpulkan, dilakukan transkripsi dengan mengindeks atau membuat daftar istilah yang paling sering dituliskan oleh informan (indeksikalitas). Selanjutnya ke tahap analisis kontekstual berupa munculnya pemahaman konteks dari istilah-istilah yang ditemukan pada tahap sebelumnya, dilanjutkan dengan mendeskripsikan atau menarasikan semua analisis kontekstual atas tinjauan keuangan dan nonkeuangan selama pembelajaran daring mahasiswa D3 akuntansi Poliban.

\section{HASIL DAN PEMBAHASAN}

Pembelajaran merupakan kegiatan menginternalisasikan ilmu pengetahuan kepada peserta didik/belajar. Dalam prosesnya terdapat aktivitas interaktif mahasiswa sebagai peserta didik dan terdapat aktivitas pendidik/dosen sebagai pembelajar. Pembelajaran melingkupi beberapa tahap seperti perencanaan, pelaksanaan, dan evaluasi yang pendidik implementasikan pada pertemuan klasikal dengan dukungan media, alat, dan bahan yang dibutuhkan pihak yang terlibat didalamnya (Syarifudin, 2020).

Pembelajaran berisi aktifitas yang menciptakan suasana atau memberikan pelayanan agar siswa belajar, pembelajaran dengan penekanan lebih pada guru dalam upayanya untuk membuat siswa dapat belajar tidak hanya membuat adanya perubahan tingkah laku siswa (Sardiman, 2011: 20-21). Dalam teorinya, pembelajaran menawarkan panduan eksplisit bagaimana membantu orang belajar dan berkembang lebih baik yang mencakup aspek kognitif, emosional, sosial, fisikal, dan spiritual (Reigeluth, 1999).

Adapun pembelajaran daring melibatkan adanya penggunaan internet dalam proses pembelajaran dengan berbagai fitur atau aplikasi perangkat lunak tanpa harus bertatap muka secara langsung sesama pengguna (Syarifudin, 2020). Pembelajaran secara daring atau online learning juga dimaknai sebagai pembelajaran jarak jauh menggunakan perangkat komputer atau gadget yang saling berhubungan dimana dosen dan mahasiswa berkomunikasi secara interaktif.

Pembelajaran daring umumnya sebuah proses pembelajaran yang pelaksanaannya dilakukan secara virtual melalui aplikasi virtual tertentu yang telah ada dan siap guna. Walaupun dilakukan secara virtual, model pembelajaran ini juga memerlukan perhatian yang besar terhadap kompetensi yang akan diajarkan (Syarifudin, 2020) dibarengi dengan kompleksitas bersamaan yang melibatkan aspek pedagogis, psikologis, dan didaktis (Mulyasa, 2013: 100). Karenanya, pembelajaran secara daring bukan hanya kegiatan transfer atau pemindahan materi melalui media internet, atau mendistribusikan tugas dan soal-soal atau studi kasus yang dikirimkan melalui aplikasi media sosial atau surel (surat elektronik).

Pembelajaran daring juga mengharuskan adanya perencanaan, pelaksanaan, serta evaluasi seperti halnya pada model pembelajaran yang lazim diselenggarakan dalam ruangan kelas. Pembelajaran daring ini juga membutuhkan sarana dan prasarana yang mendukung agar terjadinya kelancaran proses pembelajaran. Salah satu yang menjadi perhatian adalah kelancaran jaringan sinyal operator pemancar dan tentunya ketersediaan paket data masing-masing pihak yang terlibat dalam pembelajaran daring.

\subsection{Media Pembelajaran Daring}

Media pembelajaran dalam pembelajaran daring mempunyai peranan penting agar terjadi kemudahan interaksi yang lancar antara mahasiswa dengan dosen dan prosesnya pun sesuai dengan sasaran capaian pembelajaran. Pembelajaran ini sangat bergantung dengan koneksi jaringan internet yang menghubungkan antar perangkat dosen dan mahasiswa. Beberapa aplikasi yang dapat dimanfaatkan dalam 
pembelajaran dan seminar daring seperti whatsapp group, google classroom, edmodo, quizzi, jitsi, zoom, webbex, google meeting, youtube live streaming, facebook live streaming, instagram live streaming dan lain sebagainya.

Media pembelajaran daring untuk perguruan tinggi relatif berbeda dengan pembelajaran daring pelajar yang difasilitasi pemerintah dengan memberikan layanan gratis atas beberapa media aplikasi daring. Hal ini meniscayakan penyesuaian yang diperlukan pada pendekatan dan metode pembelajaran dengan perkembangan teknologi virtual. Tidak semua metode pembelajaran secara konvensional bisa dikonversikan dalam pembelajaran daring, karenanya diperlukan inovasi untuk modifikasi beberapa teknik pembelajaran daring, terlebih dengan peserta didik yang rata-rata generasi milineal yang hidup di era digital.

\subsection{Tetiba Daring: Pembelajaran Jarak Jauh dan cost of it}

Sejak diputuskan dan diumumkannya pandemic Covid 19 sebagai wabah Nasional di pertengahan Maret 2020 (Mulawarman W.G., 2020), kegiatan rutin masyarakat di Indonesia secara umum terjadi perubahan interaksinya dengan pemberlakukan physical distancing atau jaga jarak dan menghindari adanya perkumpulan orang-orang. Sebenarnya masih banyak protokol interaksi sosial di masyarakat yang berganti secara drastis dengan diumumkannya Pandemi Covid19 sebagai wabah Nasional.

Perubahan tersebut juga berdampak pada kegiatan pembelajaran di semua lingkungan pendidikan, termasuk di lingkungan Politeknik Negeri Banjarmasin (Poliban). Pengambil kebijakan di Poliban pun menetapkan perubahan mendadak dengan pemberlakuan pembelajaran jarak jauh (PJJ) atau Belajar Dari Rumah (BDR) yang juga dikenal sebagai pembelajaran daring. Pembelajaran daring ini sebagai bentuk physical distancing antara dosen dan mahasiswanya selama masa pandemic covid 19.

Perubahan tersebut sedikit banyak membawa dampak yang lumayan terasa bagi semua pihak baik dosen, mahasiswa dan juga civitas akademik lainnya. Poliban sebagai perguruan tinggi vokasional sudah menjadi karakteristiknya sebagai tempat pembelajaran keterampilan teknikal yang bersifat praktis dan hal ini mewajibkan adanya interaksi langsung antara dosen dan mahasiswanya. Tentunya menjadi keluhan massal yang ditemui ketika model pembelajaran langsung tetiba diminta menjadi model daring, namun demi kebaikan bersama dan menghindari terjadinya penyebaran wabah Covid 19 yang lebih massif, pembelajaran daring pun tetap dilakoni.

Perubahan pembelajaran yang secara normal dengan pembelajaran langsung menjadi pembelajaran daring tentunya menciptakan adanya fenomena tersendiri yang menarik untuk ditelaah dan dicarikan penyelesaiannya jika mempunyai permasalahan tersendiri. Kegiatan pembelajaran daring di lingkungan program studi D3 Akuntansi juga mempunyai fenomena tersendiri yang menarik untuk diungkap. Setelah hampir 1 semester menjalani pembelajaran daring terhitung sejak pertengahan Maret 2020 hingga awal Juli 2020, tentunya banyak kendala dan keluhan terkait kegiatan utama di lingkungan pendidikan tersebut.

Pengambilan data dilakukan terkait informasi dan pengalaman mahasiswa prodi D3 Akuntansi selama menjalani pembelajaran daring. Data diperoleh dengan meminta empat orang mahasiswa untuk membuat tulisan atau diskripsi singkat perbandingan pengeluaran mereka selama pembelajaran daring dan pembelajaran luring sebelumnya. Fenomena pembelajaran daring bagi kebanyakan orang dianggap menjadi moment untuk menjedakan manusia sebagai makhluk sosial, dengan pemberlakuan jarak fisikal (physical distancing) sebagai salah satu upaya menghambat penyebaran covid 19 (Allo, 2020; Sujarwo dkk, 2020). 
Tabel 1. Perbandingan Keuangan Kuliah Tatap Muka dan daring Mahasiswa 1

Perbandingan Keuangan

Saat Kuliah Daring dan Tatap Muka per Minggu

\begin{tabular}{lrr} 
& Tatap Muka & Daring \\
\hline Kuota & Rp. 40.000 & Rp. 70.000 \\
Trasportasi & 30.000 & - \\
Uang Makan & 65.000 & - \\
Uang Jajan & 100.000 & 200.000 \\
Jalan dgn Teman & 75.000 & - \\
Fotocopi Materi & 20.000 & -
\end{tabular}

Total

Rp. 330.000

Rp. 270.000

Tabel 2. Perhitungan Pengeluaran pembelajaran luring dan daring Mahasiswa 2

\begin{tabular}{|c|c|c|}
\hline Jenis Biaya & Kuliah Tatap Muka & Kuliah Secara Daring \\
\hline Transpotasi (Uang & Rp. $10.000 \times 22$ hari $=$ Rp. & Tidak ada biaya \\
\hline Bensin) & 220.000 & transportasi \\
\hline Saku (Uang Jajan) & Rp. $20.000 \times 22$ hari $=$ Rp. & Tidak ada uang Saku \\
\hline Kuota Internet & $\begin{array}{r}440.000 \\
\text { Rp. } 12.000 / 4 \text { x } 30 \text { hari }= \\
\text { Rp. } 90.000\end{array}$ & $\begin{array}{r}\text { Rp. } 19.000 / 5 \times 30 \text { hari }= \\
\text { Rp. } 114.000\end{array}$ \\
\hline $\begin{array}{l}\text { Total Biaya } \\
\text { Perbulan }\end{array}$ & Rp. 750.000 & Rp. 114.000 \\
\hline
\end{tabular}

Kondisi ini tentunya pembawa perubahan kebiasaan baru yang dilihat dari perspektif keuangan seakan ada blessing in disguise, berikut pengakuan mereka atas perubahan itu:

"Menurut saya, jika dilihat dari segi keuangan, kuliah secara tatap muka lebih membutuhkan biaya yang besar dibandingkan dengan kuliah secara online. Hal ini dikarenakan beberapa biaya yang dikeluarkan pada saat kuliah tatap muka lebih banyak yaitu mulai dari biaya bensin, uang makan, dan juga masih membutuhkan kuota internet. Beda hal nya dengan kuliah online yang hanya mengeluarkan biaya untuk kuota internet. Berhubung jarak rumah saya dengan kampus sekitar kurang lebih 25 menit perjalanan, jadi biasanya saya beli bensin Rp. 10.000 perhari untuk pulang pergi”. (Mahasiswi 1)

“...untuk saya secara pribadi kuliah daring ini malahan lebih menguntungkan dibanding kuliah langsung. Menguntungkan disini dalam hal secara financial, bukan saya menganggap kuliah daring ataupun keadaan pandemi sekarang lebih baik. Bisa saya katakan menguntungkan, karena dalam beberapa aspek keuangan saya khususnya untuk pengeluaran jauh lebih sedikit dibanding kuliah langsung...dibandingkan dengan kuliah secara langsung, ada begitu banyak pengeluaran yang bahkan tidak terkontrol... seperti tugas, fotocopy materi, dsb". (Mahasiswi 2)

Kedua pernyataan mengkonfirmasi adanya penurunan pengeluaran keuangan mereka sebagai mahasiswa ketika pembelajaran daring dilaksanakan. Penurunan atau penghematan atas pengeluaran tersebut dikarenakan adanya beberapa kegiatan yang biasanya mereka lakukan ketika kondisi pembelajaran normal tidak lagi mereka lakoni dan hal ini tentunya berbuntut pada tidak adanya biaya yang harus mereka keluarkan. Beberapa pendapat pun mengiyakan penghematan pengeluaran mereka ketika pembelajaran daring berlangsung, artinya pembelajaran 
daring memang memberikan keuntungan terselubung bagi sebagian informan jika dilihat dari perspektif keuangan, bahkan mereka (para informan) ada yang membuatkan simulasi perhitungan sederhana perbandingan pengeluaran.

Tabel 1 dan Tabel 2 membandingan hitung-hitungan keuangan sederhana versi mahasiswa yang mana menunjukkan jumlah pengeluaran mereka yang lebih sedikit ketika pembelajaran dilakukan secara daring ketimbang perkuliahan langsung ke kampus. Mereka meninjau sendiri berapa jumlah pengeluaran yang mereka habiskan di antara 2 pendekatan pembelajaran tersebut.

Jenis pengeluaran yang dihitung belum termasuk untuk biaya kos setiap bulannya bagi mahasiswa yang bukan penduduk di sekitaran lingkungan kampus ketika perkuliahan dlakukan secara tatap muka atau luring. Adapun tentang tinjauan nonkeuangan mahasiswa memaknainya sebagai atas kenyamanan, kemudahan dan lainnya dalam proses pembelajaran daring dan hal tersebut bisa terungkap dari beberapa pernyataan mereka berikut:

"...kuliah online dari sisi negatifnya adalah banyak tugas yang membuat saya harus terus menatap layar handphone atau laptop, yang mana pasti akan berdampak kepada kesehatan mata, yang terkadang membuat mata saya lelah dan pusing. Namun kuliah secara langsung lebih efisien, karena kuliah secara langsung membuat saya lebih paham materi dan lebih memudahkan saya untuk pertanya kepada dosen terkait materi yang tidak saya mengerti. Juga saya dapat bertemu dan bercanda dengan teman-teman di kelas". (Mahasiswi 3)

"Kuliah Daring: Sering miss komunikasi karena jaringan, entah melalui video atau chat. Kuliah Biasa: Lebih positif pembawaannya karena bertemu banyak orang. Kuliah Daring: Tugas lebih menumpuk karena tiap pertemuan dosen memberi tugas. Kuliah Biasa: Kadang lebih mudah mencerna materi daripada daring dengan waktu terbatas dan tugasnya". (Mahasiswa 1)

“...kuliah secara tatap muka rasa nyamannya sangat terasa saat berinteraksi secara langsung dengan dosen maupun teman-teman, selain itu bisa menggunakan fasilitas yang ada, internetan gratis dan baca buku kapan saja”. (mahasiswi 4)

Mahasiswi 3 menunjukkan ketidaknyamanan atau ketidaksukaannya pada pembelajaran daring dengan menyebutkan sisi negatif yang dikaitkan dengan gangguan pada masalah kesehatan jika terlalu lama berhadapan dengan gadget sebagai media dalam pembelajaran daring. Sisi negatif ini adalah aspek nonkeuangan yang diungkapkannya dan dirasakan menjadi sebuah ketidaknyamanan dalam proses pembelajaran daring. Ketidaknyaman Mahasiswi 3 ini juga di-amin-i oleh pernyataan tertulis Mahasiswi 4 yang secara langsung menyatakan kenyamanannya apabila perkuliahan dilakukan secara tatap muka dan berinteraksi langsung dengan dosen maupun teman-temannya.

Kenyamanan sebagai aspek nonkeuangan yang menjadi perhatian para informan di penelitian ini sebagai makhluk sosial yang senantiasa memiliki ketergantungan dengan orang lain (Tambak, 2017). Mahasiswa 1 pun memaknai kenyamanan dengan istilah "lebih positif" dan "lebih mudah mencerna" materi pembelajaran ketika dilakukan secara biasa atau tatap muka langsung. Kenyamanan juga dimaknai Mahasiswi 2 sebagai aspek nonkeuangan yang diharapkan segera kembali. 
Ungkapan yang diambil dari beberapa mahasiswa sebatas perwakilan atas pandangan mereka terkait pembelajaran daring yang disorot dari perspektif keuangan dan nonkeuangan adalah temuan dan hasil penelitian ini. Sederhannya, walaupun secara financial pembelajaran daring terlihat lebih ekonomis, namun ada hal non finansial lainnya yang tetap menyisakan ketidaknyaman bagi mereka dalam proses pembelajaran daring. Di beberapa pernyataan mereka, ada harapan dan doa agar wabah covid 19 berlalu dan hal ini menandakan bahwa mereka mengharap proses pembelajaran mereka akan memberikan keahlian dan keterampilan optimal bagi mereka melalui model pembelajaran secara langsung di kampus. Mereka menginginkan kembali pembelajaran luring seperti sediakala ketika wabah covid 19 belum merebak. Mereka merindukan pembelajaran luring untuk segera dibuka kembali agar kemudahan mendapatkan penjelasan secara langsung dari dosen serta suasana belajar bersama secara langsung yang menstimulus semangat mereka untuk lebih giat dalam belajar.

\section{SIMPULAN}

Pembelajaran daring dari perspektif keuangan membuat adanya penghematan jika dibandingkan dengan pembelajaran luring, namun secara nonkeuangan (terlepas dari kuota data dan jaringan internet yang stabil yang juga diperlukan di pembelajaran daring), terungkap adanya ketidaknyamanan mahasiswa dan bisa dikatakan sebagai keluhan mahasiswa selama pembelajaran daring. Ketidaknyaman tersebut berupa keluhan dalam memahami materi atau subjek pembelajaran selama kuliah daring. Fenomena pembelajaran daring ketika ditinjau dengan perspektif keuangan dan nonkeuangan pada mahasiswa D3 akuntansi Poliban, bisa saja berbeda pada lingkungan atau situs lainnya, hal ini bisa menjadi tantangan untuk penelitian selanjutnya. Ketidaknyaman dan kerinduan mereka untuk belajar secara langsung memang sudah fitrahnya manusia sebagai makhluk sosial yang membutuhkan interaksi langsung dalam proses kehidupan, termasuk dalam proses pembelajaran. Ketidaknyamanan yang menjadi aspek nonkeuangan bisa diminimalisir dengan pembelajaran interaktif yang lebih sering melalui video conference dan pemberian tugas kreatif dan inovatif yang disesuaikan dengan minta mereka. Penelitian selanjutnya bisa menggali model pembelajaran daring mana yang lebih mahasiswa minati dan memberikan pemahaman yang lebih baik selama sesi pembelajaran daring yang tidak pasti kapan berakhirnya. Wallahu'alam.

\section{REFERENSI}

Allo, M. D. (2020). Is the online learning good in the midst of Covid-19 Pandemic? The case of EFL learners. Jurnal Sinestesia, 10(1), 1-10.

Daniel, J. (2020). Education and the COVID-19 pandemic. Prospects, 49(1), 91-96.

Firman, F., \& Rahayu, S. (2020). Pembelajaran online di tengah pandemi covid-19. Indonesian Journal of Educational Science (IJES), 2(2), 81-89.

Handarini, O. I. dan S. S. Wulandari (2020). Pembelajaran Daring Sebagai Upaya Study From Home (SFH) Selama Pandemi Covid 19. Jurnal Pendidikan Administrasi Perkantoran (JPAP) . Vol. 8(3), 496-503.

Laili, Nurul (2020). Aspek Psikologi Pembelajaran Daring Masa Pandemi Covid-19 Dengan Capaian Indeks Prestasi Kumulatif Mahasiswa Vokasi. Jurnal Imiah Pamenang. 2(2), 7-17.

Lassoued, Z., Alhendawi, M., \& Bashitialshaaer, R. (2020). An exploratory study of the obstacles for achieving quality in distance learning during the COVID-19 pandemic. Education Sciences, 10(9), 232. 
Mulawarman, W. G. (2020). Persoalan Dosen dan Mahasiswa Masa Pandemik Covid 19: Dari Gagap Teknologi Hingga Mengeluh Boros Paket Data. Prosiding Seminar Nasional Hardiknas. 1, 37-46.

Mulyasa (2013). Pengembangan dan Implementasi Kurikulum 2013. Bandung: Remaja Rosadakarya

Novita, D., \& Hutasuhut, A. R. (2020). Plus Minus Penggunaan Aplikasi Aplikasi Pembelajaran Daring Selama Pandemi Covid 19. Medan: Unimed.

Reigeluth, Charles M., Moore, Julie. (1999) Cognitive education and the cognitive domain. Instructional-design theories and models: A new paradigm of instructional theory, (2), 51-68

Sujarwo, S., Sukmawati, S., Akhiruddin, A., Ridwan, R., \& Siradjuddin, S. S. S. (2020). An Analysis of University Students' Perspective on Online Learning in the Midst of Covid-19 Pandemic. Jurnal Pendidikan dan Pengajaran, 53(2), 125-137.

Syarifudin, A. S. (2020). Impelementasi Pembelajaran Daring Untuk Meningkatkan Mutu Pendidikan Sebagai Dampak Diterapkannya Social Distancing. Jurnal Pendidikan Bahasa dan Sastra Indonesia Metalingua, 5(1), 31-34.

Tahir, G. (2015). Sinergitas Ilmu Dan Adab Dalam Perspektif Islam. Jurnal Adabiyah, 15(1), 18-29.

Tambak, S. (2017). Metode Cooperative Learning dalam Pembelajaran Pendidikan Agama Islam. Al-Hikmah: Jurnal Agama Dan Imu Pengetahuan, 14(1), 1-17.

Windhiyana, E. (2020). Dampak Covid-19 terhadap kegiatan pembelajaran online di sebuah perguruan tinggi kristen di Indonesia. Perspektif Ilmu Pendidikan, 34(1), 1-8. 